\title{
Research on Enterprise Logistics Management under Sharing Mode
}

\author{
Jie $\operatorname{Sun}^{1 *}$, Liwen $\operatorname{Sun}^{1}$ \\ ${ }^{1}$ Shandong Institute of Commerce and Technolog, Jinan, China
}

\begin{abstract}
Based on the background of the digital age, in order to solve the problem of enterprise logistics management in the sharing economy environment, summarized and put forward from academic research and enterprise practice, there are two core problems that enterprises have insufficient understanding of the sharing economy and insufficient application of the sharing economy model. Further constructed by shared mode of logistics management mode, building procurement, production, storage and sales quadruple logistics information sharing platform. This article focuses on the improvement of the enterprise logistics system under the sharing mode, exploring the design of the top-level sharing platform, building enterprise alliances, and realizing information sharing. In this way, actively promote the research and development of enterprise logistics management in the sharing economy environment.
\end{abstract}

\section{Introduction}

The development of the digital economy era is driving social and economic transformation. With the continuous upgrading and application of network information technology, the traditional financial management model has been impacted and challenged. Important issues facing modern enterprises include: effective allocation of resources, optimization of business processes, implementation of effective management and enhancement of value reconstruction. The sharing economy brings a resource-saving business model, can tap the economies of scale and scope of the market, and provides a new way for the enterprise logistics industry to reduce costs, increase efficiency, and optimize and upgrade. In 2017, the "Opinions on Further Promoting Logistics Cost Reduction and Efficiency Increase to Promote the Development of the Real Economy" put forward the requirements for the development of a new form of "Internet + " resource supply and demand balance and the use of platform advantages to achieve efficient resource allocation. In the "Guiding Opinions on Promoting the Development of the Sharing Economy", guiding opinions on the development of the sharing economy are put forward. Academic research has a clear definition of the connotation of the sharing economy. It is defined that the sharing economy is the realization of resource transactions between organizations and individuals through an information platform ${ }^{[1]}$, which is the use of technological means to enhance the utilization of idle resources under the condition of separation of ownership and use rights The new paradigm of efficiency has five basic elements of idle resources, real demand, connection mechanism, information flow, and income ${ }^{[2]}$, emphasizing the elastic matching between the supply side and the demand side ${ }^{[3]}$. In addition, Yu Hang ${ }^{[4]}$ and Tian Fan $^{[5]}$ established sharing economy analysis frameworks from different perspectives. Yu Fengxia [6], Zhao Guanghua ${ }^{[7]}$ and Zhao Guanghui ${ }^{[8]}$ conducted applied research from the aspect of logistics resource sharing, rural e-commerce distribution and urban transportation sharing. Research and practical applications in enterprise logistics are relatively lacking. How to establish an enterprise system under the background of the sharing economy and promote the efficient development of enterprise logistics is a major issue in advancing the strategic process of strengthening the country.

\section{The status quo of enterprise logistics management mode under the sharing economy}

\subsection{Sharing economy definition}

Sharing economy refers to relying on the Internet platform to intelligently match the use of idle resources in society with diversified needs, and replace the traditional economic model of high cost and delayed incremental increase with a low-cost and high-efficiency shared stock method, thereby achieving resource improvement A new economic model for the utilization of surplus value and reducing the cost of resource use. The basic elements of the sharing economy include shared resources, sharing channels, supply and demand entities, and operating mechanisms. The basic model is to realize the sharing of idle resources between supply and demand through information exchange within the framework of the operating mechanism.

The logistics model under the sharing economy is a new model for the allocation of logistics resources based 
on the sharing economy. By integrating fragmented social logistics service resources, information interconnection is used to match the diversified logistics needs of the society and meet the needs of social services at low cost. Through homogenous resource sharing and heterogeneous resource synergy among enterprises, it promotes the balance of resource supply and demand and the optimization and upgrading of service capabilities, effectively breaking the limitations of individual enterprise service capabilities, optimizing the combination to form a new source of profit, and realizing that the overall advantage of the system exceeds the benefits of individual independent operations sum.

\subsection{Connotation of enterprise logistics system}

An enterprise is an enterprise generally refers to a legal person or a legal person that uses various production factors (land, labor, capital, technology, entrepreneurial talent, etc.) to provide goods or services to the market for the purpose of profitability, and implements independent operation, self-financing, and independent accounting. Other socio-economic organizations. Enterprises achieve profitability through logistics procurement, product production, finished product warehouse management, and finished product sales. The enterprise emphasizes the management of the overall production process and the coordination with economic development and logistics relations. On the basis of the sharing economy, the enterprise logistics system realizes the internal and external flow of logistics information, raw materials, products in progress, and finished products through the construction of a shared platform. The sharing platform can realize large-scale, high-efficiency, low-cost resource sharing, and the platform construction must be led by relevant departments and integrated into the enterprise logistics service process and operation links.

\section{Problems in enterprise logistics management under shared mode}

\subsection{Insufficient awareness of the sharing economy}

Although more and more enterprises in our country have realized the importance of information-based logistics management, it is undeniable that logistics information alone cannot solve the logistics problems in enterprises, and cannot improve logistics through the application of information-based logistics management technology. Management efficiency. In addition, the problems of enterprises in production, sales, and transportation are also obvious. Problems such as imperfect systems and imperfect systems make the quality of logistics management of some enterprises not guaranteed, which may not only increase management costs due to risks, but also weaken The competitiveness of enterprises. In addition, the conservative thinking of managers is also reflected in the fact that enterprises do not have relatively independent information technology management departments. Many professionals are scattered in various departments. It is difficult to play a role through unified management and coordination. This also restricts the information logistics management to a certain extent. development of.

\subsection{Insufficient application of sharing mode}

The development of the Internet provides a more efficient platform for enterprises to carry out. It not only promotes the development of enterprises, but also promotes the logistics system of the whole society. In the network age, if logistics companies want to be more competitive, they need to scientifically select logistics technology. Among the more commonly used logistics technologies are automatic sorting, barcode technology, positioning technology, geographic information technology, etc. These technologies can be applied in different links of logistics management to improve the efficiency of logistics management as a whole. The technical application of any link is not sufficient. It may affect the efficiency of logistics management. In fact, the application of logistics information technology in many enterprises has reached the level of informatization, but the informatization of logistics information has caused high costs, incomplete information, etc., and there is no complete technical level and logistics information design capabilities, and it is in a sharing mode. It can achieve the purpose of improving efficiency and reducing costs, but because there are no high-level technical personnel. Either way, it will hinder enterprises to improve the efficiency of logistics management.

\section{Establish a corporate logistics management model under a shared model}

\subsection{Analysis of Sharing Mode}

Sharing resources is the foundation of the development of the sharing economy. From the perspective of the normal logistics process of the enterprise, the sharing space of resources under the current enterprise logistics system is analyzed.

The circulation of goods in an enterprise is nothing more than the following four aspects: raw material procurement, product transshipment, finished product inventory, and finished product sales. In these links, only relying on informatization will result in restriction and waste of service resources, and in some links There are scenes with incomplete service functions, so the four links of information flow and information channels need to be opened up. This requires the establishment of a sharing model, through which companies can improve their logistics service capabilities and reduce operating costs, so as to realize the sharing of service capabilities and resources. It can achieve sales and predictable inventory volume and expected production volume. Production can be based on sales orders or forecasted volume for production purchases, etc., reducing enterprise logistics 
management costs, improving enterprise logistics information efficiency, and achieving the purpose of increasing corporate profits.

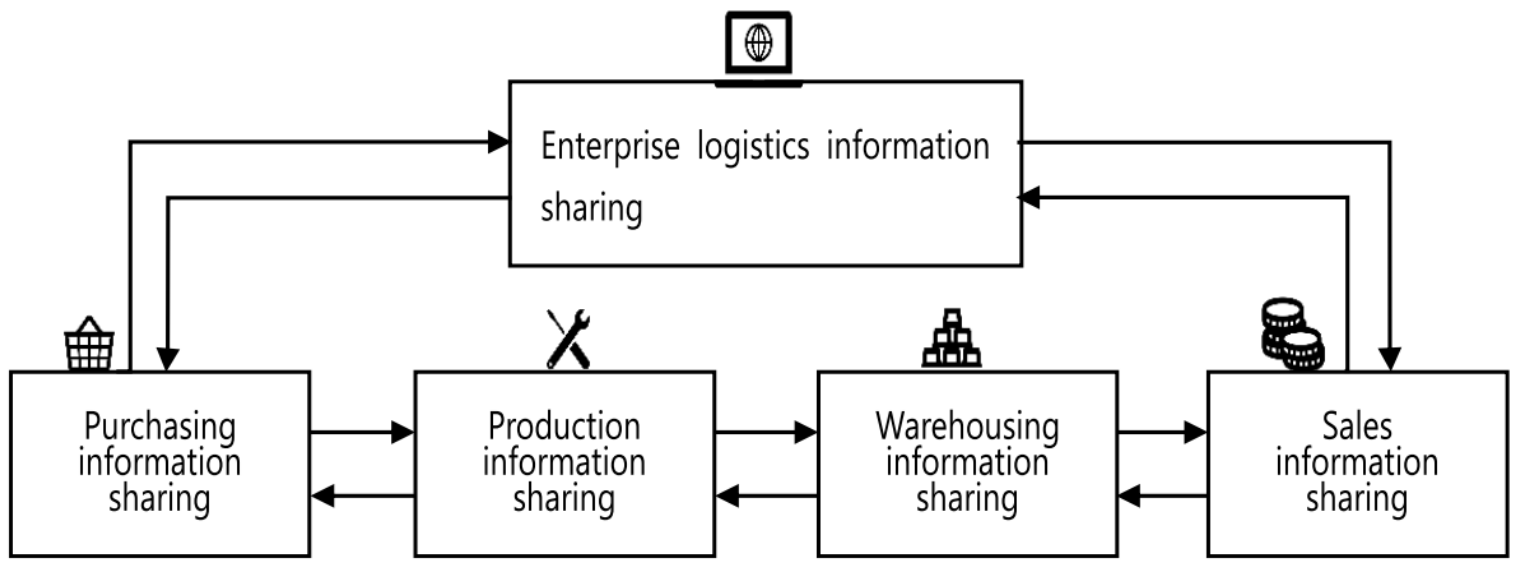

Figure 1: Enterprise logistics information sharing model

\subsection{Sharing platform construction}

Resource sharing between enterprises relies on the visualization of the platform and low transaction costs. To build an enterprise logistics service sharing platform, through integration and deployment of service resources, to achieve a dynamic balance of supply and demand.

Nowadays, the acquisition of logistics information in enterprises can only be obtained through relevant persons in charge. For example, when obtaining the information of the incoming goods flow, the only way to obtain it is the person in charge of the purchasing department. For product logistics, you need to ask the person in charge of the production department. In terms of resource sharing between enterprises, the coordinated operation of the service theme has not been realized. It is necessary for the enterprise to establish a sharing platform for coordinated operation. The sharing center platform should include the four sub-systems of the enterprise's purchasing information sharing, production information sharing, storage information sharing, and sales information sharing. The system, through the coordinated operation of subsystems, provides timely and reliable data for the management of the management. This requires the establishment of an overall logistics platform, and the step-by-step design of each part in the logistics platform, so as to achieve the purpose of logistics information sharing.

Purchasing information sharing should include information such as estimated purchase volume, purchase date, raw material arrival date, etc. Such information needs to be shared through coordination between enterprises. Under the sharing mode, the maturity of thirdparty logistics, the concept of cooperative logistics for win-win cooperation, and the rapid development of logistics information technology provide feasibility for the logistics information sharing model.

In the procurement model, subject to the constraints of the shipper, the logistics information sharing of the procurement platform is through the third-party logistics company or the seller's company. In order to obtain more business, the third-party logistics company needs to obtain more and effective logistics information. Such a large logistics information sharing platform can provide it with more logistics information, so third-party logistics companies actively participate.

Purchasing logistics information sharing can achieve win-win cooperation under this mode, greatly reducing costs and saving resources, and as it becomes more and more popular, different participants actively join the platform. Finally, the rapid development of logistics information platform technology provides technical support for it. Including the popularization of mobile Internet technology and the mature development of big data technology, the platform big data logistics enterprise information sharing model is widely used.

In the production information sharing, the production sharing platform sharing mode has the following functions. 1) Information service function. Enter, publish, query, and count raw materials. Including comprehensive information, transaction information, scheduling information, cargo tracking information, etc. 2) Logistics operation management function. The platform can sort and manage different raw materials in different ways. 3) Production management function: For the estimated demand output and specific demand time, the production time can be reversed from time to help the production department make production decisions. 4) Auxiliary decision-making function. Using the large amount of data accumulated for a long time by the logistics information platform, through mathematical modeling and other methods, the data is mined and refined, and the production efficiency is analyzed, the yield rate and the excellent product rate are analyzed, so as to achieve the optimization of the production sharing mode under the sharing mode. purpose. For example, global or local logistics optimization, capacity analysis of distribution centers, distribution network plans, etc., can help people make auxiliary decisions.

In the warehousing sharing model: relying on the sharing center model, in order to realize the sharing of warehousing resources while reducing warehousing costs 
as much as possible, the virtual inventory management theory is used as the main basis for the design of the supply chain warehousing sharing model. Based on big data analysis technology, combined with virtual inventory management theory, and the status of each enterprise, the operating mechanism of the warehousing sharing mode is designed to achieve the purpose of assisting decisionmaking and sharing logistics information. The model includes three levels: the management layer, the storage resource data layer, and the execution layer of each department of the enterprise. First of all, the management level makes decision based on the relevant data of the warehousing resource database; among them, the resource layer is a database that composes the data of the free warehousing resources, warehousing facilities and equipment, inventory and other resources actually owned by all nodes in the supply chain. The content in is provided by each node enterprise in the supply chain, and each node enterprise must be responsible for the authenticity of the information. This is the basis and prerequisite for ensuring that storage resources can be shared scientifically and accurately. The executive layer is based on the virtual coordination center, and the main task is to use big data technology to analyze and process the resource information in the database of the resource layer to provide decision-making basis for the decision-making layer. The specific implementation process of the executive level includes four aspects: 1. Sharing purchases, according to sales orders or sales calculations, and independently measuring whether the production line capacity can complete sales orders, the quantity of raw materials required, and the time required for raw materials, etc.; 2. Sharing production, according to sales Order or sales forecast, combined with the arrival time of raw materials, coordinate production to improve the efficiency of production and sales of the enterprise, 3. Product storage sharing, according to the change of logistics information shared by production, timely adjustment of the finished product inventory situation, 4 . Share sharing : According to the completion status of the sales order and the sales logistics status, timely update the inventory status to achieve the logistics information sharing mode. When there are goods that need to be put in or out of the warehouse, according to the cargo information provided by the system, the warehouse and the loading and unloading operations are carried out according to the final optimal path, reducing the operation path of the forklift, improving logistics efficiency and reducing warehouse logistics costs. Through the sharing of the above modes, the internal logistics information of the enterprise can be updated in time, which is conducive to making the fastest route setting, improving the turnover speed of the enterprise's goods, and improving the efficiency of the enterprise's operation.

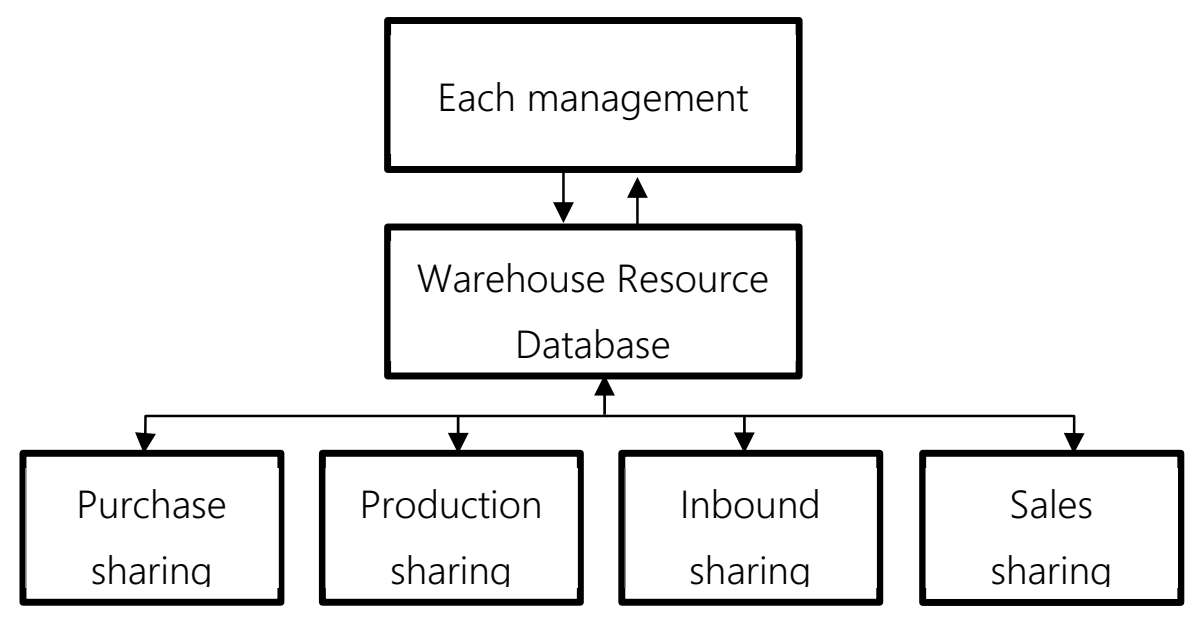

Figure 2: Enterprise logistics information sharing platform

In the sales sharing model:

In the sales process of an enterprise, the three most important parts are key items such as goods issuance, tax invoicing, and payment recovery. In order to achieve financial sharing services and open up the organic connection of business, financial, and tax data, it is necessary to establish an accounts receivable management system At the same time, it is necessary to combine the tax invoice financial application platform to realize the online issuance of value-added tax invoices and establish the sharing of cargo logistics information. Relevant data is transmitted in real time in these three systems, realizing data integration and high automation.

1. Optimize the invoice management process. Customers and salespersons apply for invoicing, and the data is transmitted to the "Internal Tax Invoice
Management System" for review. After authorization and approval by the production and operation department and contract management department, there will be text messages, emails, WeChat, etc. to remind you of successful invoicing. The hospital has set up multiple invoicing points. If you need paper invoices, you can go to the nearest designated place to print out, and electronic invoices will be sent to the designated mailbox. Or the invoice can be issued along with the logistics information. After the other party confirms the receipt of the goods, the system will automatically issue a special value-added tax invoice based on the submitted data, or issue a special value-added invoice based on the company's payment status to reduce the occurrence of bad debt.

2. Optimization of collection management process. In the development process of enterprises, the collection of 
receivables has always been a major problem. In the sharing mode, logistics information is used as the basis for payment recovery. The business is divided into cash on delivery and payment back within a period of time after delivery. At the stage of goods delivery, the logistics information and transfer information can be shared with each other as a condition for issuing invoices. When the logistics arrives and the bank receives the payment, the sharing center can automatically issue the invoice to the customer; within a period of time after the arrival of the goods In the case of payment, you can confirm the logistics information first, and automatically set the payment reminder mechanism through the sharing center. After the logistics confirms the arrival of the goods, the payment return mechanism is turned on. When the bank confirms the payment, the payment reminder setting is automatically turned off. As shown below:

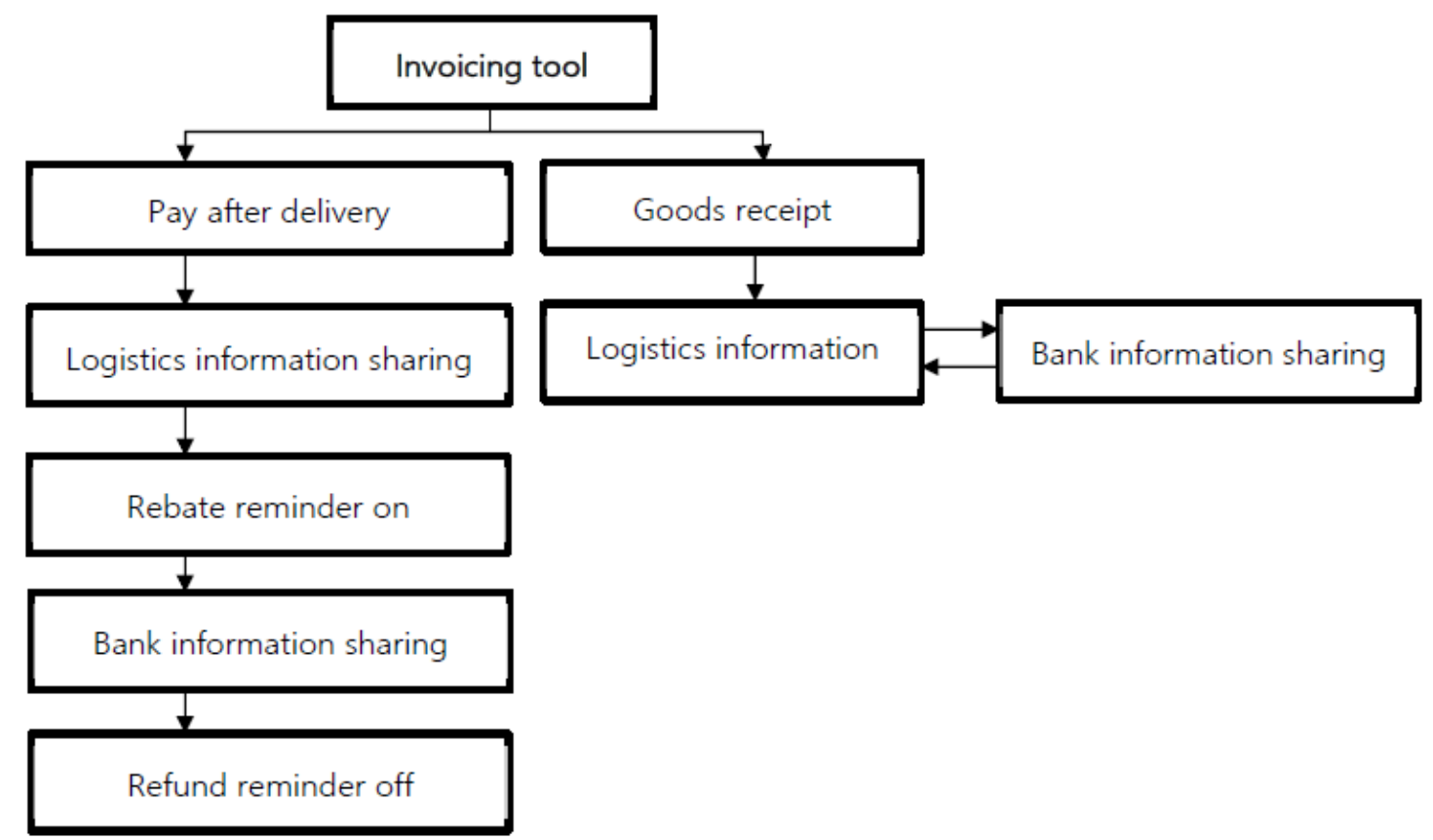

Figure 3: Enterprise collection optimization model

Invoice management, income management status and repeated taxation analysis, relying on Internet technology, establish a financial sharing center, move the traditional time-consuming and laborious work of invoicing, reconciliation, and collection to online processing, and fully realize the integration from business to finance , Through the reengineering of business financial processes, to help companies reduce operating costs, improve efficiency, prevent tax risks, and reduce losses; and share corporate business data, financial data and customer information through the financial sharing center.

\section{Conclusion}

\subsection{Top-level design sharing platform}

The construction of the logistics service sharing platform must be planned and designed from the top level, and the government will take the lead in building the platform and guiding enterprises to participate together, standardize the platform operation process, and optimize the profit distribution mechanism. By connecting business systems to the platform, enterprises can realize information sharing and business process collaboration among cooperative enterprises in the service chain, and improve service capabilities and service efficiency. Rely on the advantages of platform resource sharing services, eliminate corporate resource monopoly behavior and information barriers, efficiently allocate resources, and balance income distribution.

\subsection{Establish enterprise cooperation alliance}

The enterprise cooperation alliance is composed of enterprises with homogeneous resources and participates in the formulation of various rules of the alliance. The alliance has the function of formulating cooperation rules, standard cooperation procedures, and monitoring cooperation risks. Based on the framework of the alliance, guide enterprises to participate in the sharing of idle resources, regulate the behavior of enterprises in sharing cooperation, and reduce the risk of enterprise resource sharing.

\subsection{Strengthen the degree of information sharing}

In the business model, a closed business loop is formed from the buyer to the seller, which means that any company is both a buyer and a seller. In this process, the logistics information sharing degree of the seller is strengthened. It is also to increase the degree of sharing of the purchaser's logistics information, so as to enhance the degree of informatization, gradually reduce the waste of 
corporate and social resources, and increase the utilization rate of social resources.

\section{Acknowledgement}

Finally, I would like to thank Mr. Ma Zhenxiang and Mr. Cui Faqiang for supporting me in the project research. At the same time, I would like to thank Shandong Vocational and Technical College of Commerce for the financial support for my research. Thank you all.

\section{References}

1. Liu Yi, Xia Jiechang. Research trends in theories and policies of sharing economy[J]. Economics, 2016(04): 116-125.

2. Chris J. Martin. The sharing economy: A pathway to sustainability or a nightmarish form of neoliberal capitalism?. 2016, 121:149-159.

3. Jia Kang, Su Jingchun. On supply-side reforms[J]. Management World, 2016(03):1-24.

4. Yu Hang, Tian Lin, Jiang Guoyin, Chen Yun. Sharing Economy: Theoretical Construction and Research Progress[J]. Nankai Management Review, 2018, 21(06): 37-52.

5. Tian Fan. Theoretical research on the interaction of talent drain, economic growth and talent policy[J]. China Human Resources Development, 2016(13):7983.

6. Yu Fengxia. Thoughts and suggestions on improving the social credit system and promoting the development of my country's sharing economy[J]. Electronic Government Affairs, 2018(08): 81-87.

7. Zhao Guanghua. Rural e-commerce joint distribution operation model based on shared logistics[J]. China Circulation Economy, 2018, 32(07): 36-44.

8. Zhao Guanghui. Research on risk control of logistics enterprises under the background of "Internet +"[J]. Modern Management Science, 2017(08): 69-71.

9. Faqiang Cui. Analysis on the Impact of Big Data on Enterprise Management Decisions[A]. Institute of Management Science and Industrial Engineering. Proceedings of 2019 3rd International Conference on Economics, Management Engineering and Education Technology (ICEMEET 2019) [C]. Institute of Management Science and Industrial Engineering: Computer Science and Electronic Technology International Society, 2019: 5.

10. The Sustainability Paradox of the Sharing Economy. Hans Verboven,Lise Vanherck. Uwf Umwelt Wirtschafts Forum. 2016 